\title{
Long-Term Outcome of Open or Endovascular Repair of Abdominal Aortic Aneurysm
}

\author{
Jorg L. De Bruin, M.D., Annette F. Baas, M.D., Jaap Buth, M.D., \\ Monique Prinssen, M.D., Eric L.G. Verhoeven, M.D., Philippe W.M. Cuypers, M.D., \\ Marc R.H.M. van Sambeek, M.D., Ron Balm, M.D., Diederick E. Grobbee, M.D., \\ and Jan D. Blankensteijn, M.D., for the DREAM Study Group*
}

\section{A BSTRACT}

\section{BACKGROUND}

For patients with large abdominal aortic aneurysms, randomized trials have shown an initial overall survival benefit for elective endovascular repair over conventional open repair. This survival difference, however, was no longer significant in the second year after the procedure. Information regarding the comparative outcome more than 2 years after surgery is important for clinical decision making.

\section{METHODS}

We conducted a long-term, multicenter, randomized, controlled trial comparing open repair with endovascular repair in 351 patients with an abdominal aortic aneurysm of at least $5 \mathrm{~cm}$ in diameter who were considered suitable candidates for both techniques. The primary outcomes were rates of death from any cause and reintervention. Survival was calculated with the use of Kaplan-Meier methods on an intentionto-treat basis.

\section{RESULTS}

We randomly assigned 178 patients to undergo open repair and 173 to undergo endovascular repair. Six years after randomization, the cumulative survival rates were $69.9 \%$ for open repair and $68.9 \%$ for endovascular repair (difference, 1.0 percentage point; $95 \%$ confidence interval $[\mathrm{CI}],-8.8$ to $10.8 ; \mathrm{P}=0.97)$. The cumulative rates of freedom from secondary interventions were $81.9 \%$ for open repair and $70.4 \%$ for endovascular repair (difference, 11.5 percentage points; 95\% CI, 2.0 to 21.0; $\mathrm{P}=0.03$ ).

\section{CONCLUSIONS}

Six years after randomization, endovascular and open repair of abdominal aortic aneurysm resulted in similar rates of survival. The rate of secondary interventions was significantly higher for endovascular repair. (ClinicalTrials.gov number, NCT00421330.)
From the Department of Surgery, Vrije Universiteit Medical Center, Amsterdam (J.L.D.B, J.D.B.); the Julius Center for Health Sciences and Primary Care, University Medical Center, Utrecht (A.F.B., M.P., D.E.G.); the Department of Surgery, Catharina Hospital, Eindhoven (J.B., P.W.M.C., M.R.H.M.S.); the Department of Surgery, Academic Hospital, Groningen (E.L.G.V.); the Department of Surgery, Erasmus Medical Center, Rotterdam (M.R.H.M.S.); and the Department of Surgery, Academic Medical Center, Amsterdam (R.B.) - all in the Netherlands. Address reprint requests to Dr. Blankensteijn at the Department of Surgery, VU Medical Center, P.O. Box 7057, 1007 MB Amsterdam, the Netherlands, or at j.blankensteijn@vumc.nl.

Drs. De Bruin and Baas contributed equally to this article.

*The members of the Dutch Randomized Endovascular Aneurysm Repair (DREAM) study group are listed in the Appendix.

N Engl J Med 2010;362:1881-9.

Copyright (c) 2010 Massachusetts Medical Society. 
ANDOMIZED TRIALS HAVE SHOWN THAT endovascular repair offers a perioperative survival benefit over open repair for patients with a large abdominal aortic aneurysm. However, this advantage is not sustained beyond 2 years after surgery. ${ }^{1-4}$ There is concern that endovascular repair lacks durability, with the possibility of an increased risk of late rupture, ${ }^{5}$ and that more reinterventions are required in patients undergoing this technique. Long-term outcome data from these trials are considered to be of crucial importance in deciding which treatment option a patient should be offered.6,7 To date, only limited data beyond 2 years after randomization have been reported. To provide long-term data, we analyzed the results of the Dutch Randomized Endovascular Aneurysm Repair (DREAM) trial after a median of 6.4 years. ${ }^{1,3}$

METHODS

\section{STUDY DESIGN}

The design and methods of this trial have been described in detail previously. ${ }^{8}$ In brief, the DREAM trial was a multicenter, randomized trial conducted at 26 centers in the Netherlands and 4 centers in Belgium. The institutional review board at each center approved the original trial protocol and the follow-up extension. The study was performed according to the principles of the Declaration of Helsinki.

The trial was funded by a grant from the Netherlands National Health Insurance Council. No support was provided by pharmaceutical or medical-device companies. The sponsor had no role in the design or conduct of the study; in the collection, management, analysis, or interpretation of the data; or in the preparation, review, or approval of the manuscript.

\section{STUDY PATIENTS}

Patients who had an abdominal aortic aneurysm measuring at least $5 \mathrm{~cm}$ in diameter and who were considered suitable candidates for either open or endovascular repair were enrolled after providing written informed consent. Suitability for endovascular repair was primarily determined by means of endograft-dependent anatomical criteria, whereas suitability for open repair was determined by an internist or cardiologist. Patients who required emergency aneurysm repair were excluded from the trial, as were patients with inflammatory an- eurysms, anatomical variations (e.g., horseshoe kidney), connective-tissue disease, a history of organ transplantation, or a life expectancy of less than 2 years.

Randomization to either procedure was carried out centrally with the use of a computer-generated, permuted-block sequence and stratified according to study center in blocks of four patients. The primary informed consent covered 2 years of close follow-up for all patients. For this long-term analysis, a second written informed consent was requested from all patients who had completed the initial 2 years of follow-up. Patients were asked to provide consent for continued acquisition of follow-up data for the purpose of this study and for our sending twice-yearly questionnaires on their quality of life and use of medical services. Patients were informed that the follow-up protocol after the second postoperative year would not require extra studies for trial purposes and would involve only the collection of data regarding routine clinical care.

\section{DATA COLLECTION AND FOLLOW-UP}

Follow-up visits for the initial phase of the trial were scheduled 30 days and 6, 12, 18, and 24 months after the procedure. After the initial 2 years of close follow-up, patients received a questionnaire every 6 months requesting information about the status of their mental and physical health, as well as information about visits to a general practitioner or other physicians and all hospital admissions. Follow-up for patients in the endovascular-repair group included a yearly follow-up visit and the performance of computed tomography (CT). Patients in the open-repair group were advised to see their physicians annually, but they were not actively recruited for follow-up visits during the third and fourth years after surgery. All patients were contacted by telephone 5 years postoperatively and were invited for a follow-up visit with a CT scan. Medical records were used to confirm the information that patients had provided. All data were submitted to the trial-coordination center at the Julius Center for Health Sciences and Primary Care, University Medical Center, Utrecht, the Netherlands.

For the current analysis, data acquisition was stopped on February 1, 2009. For all analyses, data were censored after the last follow-up contact or at the time the last questionnaire was returned. Patients who had declined further participation 
at 2 years or who were initially lost to follow-up were contacted directly or through their relatives or physicians. In addition, from November 2008 through February 2009, all records were scrutinized for information about reinterventions and causes of death. The information obtained in this way was incorporated into the analysis of crude survival and causes of death.

\section{PRIMARY OUTCOMES}

The long-term primary outcomes were rates of death from any cause and reintervention. An outcome-adjudication committee, consisting of five vascular surgeons, classified the causes of death and reinterventions in a blinded fashion and independently from one another. Disagreements were resolved in a plenary consensus meeting.

The causes and exact dates of death were determined by reviewing death certificates and, if necessary, by contacting the involved physicians (general practitioners, surgeons, and other specialists) and patients' relatives. In-hospital death was defined as any death occurring within 30 days after the original procedure or any death occurring more than 30 days after the original procedure but during the same hospital admission. We distinguished between cardiovascular causes of death (myocardial infarction, congestive heart failure, cardiac arrest, stroke, and ruptured aneurysm) and noncardiovascular causes of death (cancer, pulmonary conditions, and miscellaneous disorders).

A reintervention was defined as any surgical or endovascular procedure that was related to the primary aneurysm-repair procedure. The decision to perform a secondary intervention was made by the individual surgeon. Indications for reinterventions were classified into three groups: graftrelated indications (e.g., thrombo-occlusive disease, endoleak type 1 or endotension [pressure in the aneurysm sac without a detectable endoleak], endograft migration, prosthesis infection, graft-material failure, para-anastomotic aneurysm, and aneurysm rupture), wound-related indications (e.g., incisional hernia and wound infection), and local or systemic indications (e.g., bleeding, endoleak type 2 , and ileus).

\section{STATISTICAL ANALYSIS}

All data were analyzed according to the intention-to-treat principle. The completeness of follow-up was calculated as the ratio of the total observed person-time of follow-up to the potential time of follow-up in the study for the two study groups. ${ }^{9}$ Kaplan-Meier analysis was used to calculate survival and other end points, and differences between groups were compared with the use of the log-rank test. All reported P values are two-sided and have not been corrected for multiple testing.

RESULTS

\section{STUDY PATIENTS}

From November 2000 through December 2003, we randomly assigned 178 patients to undergo open repair and 173 to undergo endovascular repair (Fig. 1). Baseline characteristics are shown in Table 1. The mean age of the patients was 70 years, and $91.7 \%$ were male; $43.9 \%$ had concomitant cardiac disease.

Six patients did not undergo aneurysm repair after randomization: four declined treatment (three in the open-repair group and one in the endovascular-repair group), one died from a ruptured abdominal aortic aneurysm before undergoing open repair, and one died from pneumonia before undergoing endovascular repair. There were eight in-hospital deaths after open repair and two after endovascular repair (Fig. 1).

The median follow-up was 6.4 years (range, 5.1 to 8.2). All patients were followed for 5 years, $79 \%$ for 6 years, and 53\% for 7 years. The completeness of follow-up was $99.3 \%(11,589 / 11,673$ months) for open repair and 99.7\% (11,193/11,232 months) for endovascular repair. At the date of censoring, 106 patients had died during followup after hospital discharge (51 in the open-repair group and 55 in the endovascular-repair group) (Fig. 1). Five years after randomization, CT was performed in approximately one fourth of patients in the open-repair group and in almost all patients in the endovascular-repair group.

\section{OVERALL SURVIVAL}

Six years after randomization, the cumulative overall survival rates were $69.9 \%$ for open repair and $68.9 \%$ for endovascular repair, for a difference of 1.0 percentage point $(95 \%$ confidence interval [CI], -8.8 to $10.8 ; \mathrm{P}=0.97$ ) (Fig. $2 \mathrm{~A}$ ). The increased perioperative mortality in the openrepair group was counterbalanced by a larger number of deaths after discharge in the endovascular-repair group. An analysis of the causes of 


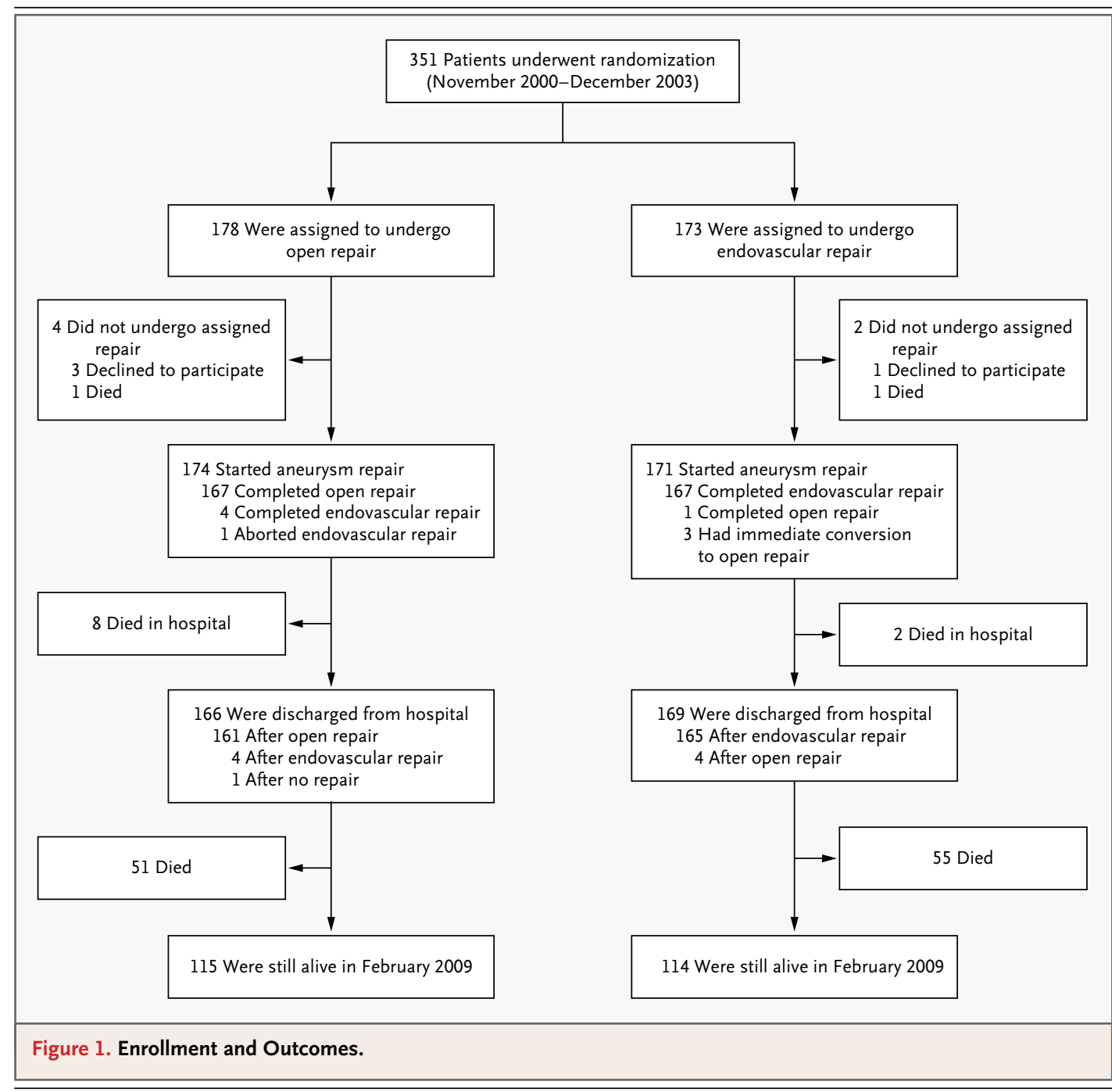

death indicated that miscellaneous rather than cardiovascular causes accounted for the larger number of deaths after discharge among patients undergoing endovascular repair (Table 2).

\section{REINTERVENTION}

Six years after randomization, the cumulative rates of freedom from secondary interventions were $81.9 \%$ for open repair and $70.4 \%$ for endovascular repair, for a difference of 11.5 percentage points (95\% CI, 2.0 to 21.0; $\mathrm{P}=0.03$ ) (Fig. 2B). After open repair, the most frequent reintervention was correction of an abdominal incisional hernia, whereas endovascular-repair reinterventions were most often performed because of endograft-related complications, such as endoleak and endograft migration (Table 3). In one patient who had crossed over from open to endovascular repair, reinterven- tion because of an occluded endograft limb was complicated by a fatal myocardial infarction.

In the open-repair group, nine patients required a second reintervention and two required a third reintervention. After endovascular repair, $14 \mathrm{pa}$ tients required a second reintervention, and 7 required a third reintervention. Endovascular procedures accounted for 5 of 41 reinterventions (12\%) in the open-repair group and 25 of 69 reinterventions $(36 \%)$ in the endovascular-repair group.

\section{DISCUSSION}

Our principal finding was that among patients with large abdominal aortic aneurysms, there was no significant difference between endovascular repair and open repair in the rate of overall survival at a median of 6.4 years. A small but signifi- 


\begin{tabular}{|c|c|c|c|}
\hline Characteristic & $\begin{array}{l}\text { Open Repair } \\
(\mathrm{N}=178)\end{array}$ & $\begin{array}{l}\text { Endovascular Repair } \\
\qquad(N=173)\end{array}$ & P Value \\
\hline Age $-y r$ & $69.6 \pm 6.8$ & $70.7 \pm 6.6$ & 0.13 \\
\hline Male sex — no. (\%) & $161(90.4)$ & $161(93.1)$ & 0.44 \\
\hline \multicolumn{4}{|l|}{$\begin{array}{l}\text { Patients with mild, moderate, or severe SVS/ISCVS } \\
\text { risk-factor score }-\% \dagger\end{array}$} \\
\hline Diabetes mellitus & 9.6 & 10.4 & 0.86 \\
\hline Tobacco use & 55.1 & 64.2 & 0.10 \\
\hline Hypertension & 54.5 & 58.4 & 0.52 \\
\hline Hyperlipidemia & 52.6 & 47.0 & 0.33 \\
\hline Carotid disease & 15.2 & 14.5 & 0.88 \\
\hline Cardiac disease & 46.6 & 41.0 & 0.33 \\
\hline Renal disease & 8.4 & 7.5 & 0.85 \\
\hline Pulmonary disease & 18.5 & 27.7 & 0.04 \\
\hline Sum of SVS/ISCVS risk-factor scores & $4.5 \pm 2.5$ & $4.4 \pm 2.5$ & 0.61 \\
\hline $\mathrm{FEV}_{1}$ - liters $/ \mathrm{sec}$ & $2.6 \pm 0.7$ & $2.5 \pm 0.7$ & 0.27 \\
\hline Body-mass index & $26.6 \pm 4.1$ & $26.3 \pm 3.4$ & 0.47 \\
\hline \multicolumn{4}{|l|}{ ASA class — no. (\%) } \\
\hline I (healthy) & $44(24.7)$ & $37(21.4)$ & 0.53 \\
\hline II (mild systemic disease) & $110(61.8)$ & $122(70.5)$ & 0.09 \\
\hline III (severe systemic disease) & $24(13.5)$ & $14(8.1)$ & 0.12 \\
\hline \multicolumn{4}{|l|}{ Medication use - no. (\%) } \\
\hline Beta-blocker & $92(51.7)$ & $76(43.9)$ & 0.17 \\
\hline Statintr & $72(41.9)$ & $63(37.3)$ & 0.44 \\
\hline Antiplatelet agent & $72(40.4)$ & $70(40.5)$ & 1.00 \\
\hline Angiotensin-converting-enzyme inhibitor & $50(28.1)$ & $58(33.5)$ & 0.30 \\
\hline Calcium-channel blocker & $32(18.0)$ & $30(17.3)$ & 0.89 \\
\hline Anticoagulant & $27(15.2)$ & $20(11.6)$ & 0.35 \\
\hline
\end{tabular}

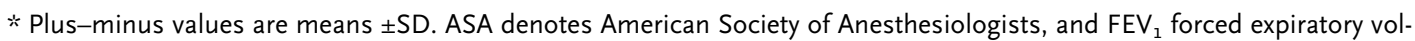
ume in 1 second. The body-mass index is the weight in kilograms divided by the square of the height in meters. Because of rounding, not all percentages total 100.

$\dagger$ The Society for Vascular Surgery/International Society for Cardiovascular Surgery (SVS/ISCVS) risk-factor score ranges from 0 (no risk factors) to 3 (severe risk factors) for each of eight domains. ${ }^{7}$ Total scores range from 0 to 24 , with higher scores indicating more risk factors.

† No data about statin use were available for six patients in the open-repair group and four patients in the endovascularrepair group.

cant difference in 30-day operative mortality in favor of endovascular repair had previously been reported in the DREAM trial and in two large, randomized trials., ${ }^{1,2,10}$ In 2-year analyses of both the DREAM trial ${ }^{3}$ and the United Kingdom Endovascular Aneurysm Repair 1 (EVAR 1) trial (Current Controlled Trials number, ISRCTN55703451), ${ }^{4}$ this apparent early benefit had already been lost. With the longer follow-up in our study, the rate of overall survival remained similar for the two procedures.
Another finding was that endovascular repair was associated with a significantly higher rate of reintervention than was open repair. This observation supports the view that the short-term survival benefit of endovascular repair is achieved at the expense of long-term problems related to endograft durability. Although these problems do not seem to translate into a long-term disadvantage in overall survival, the risks associated with reintervention need to be assessed in larger studies. It is important to recognize that reinter- 


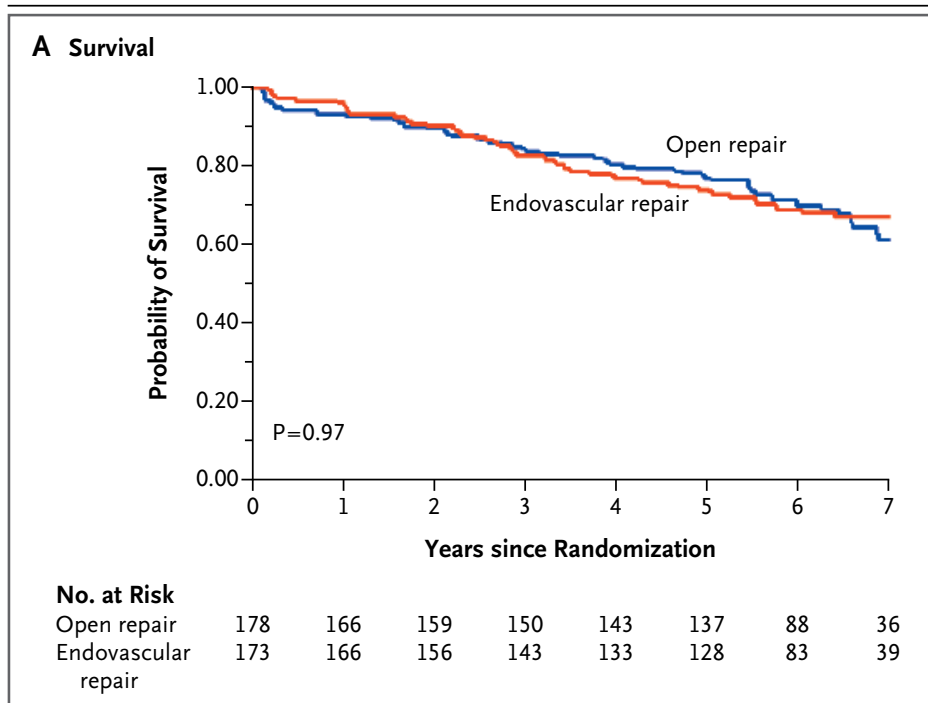

B Freedom from Reintervention

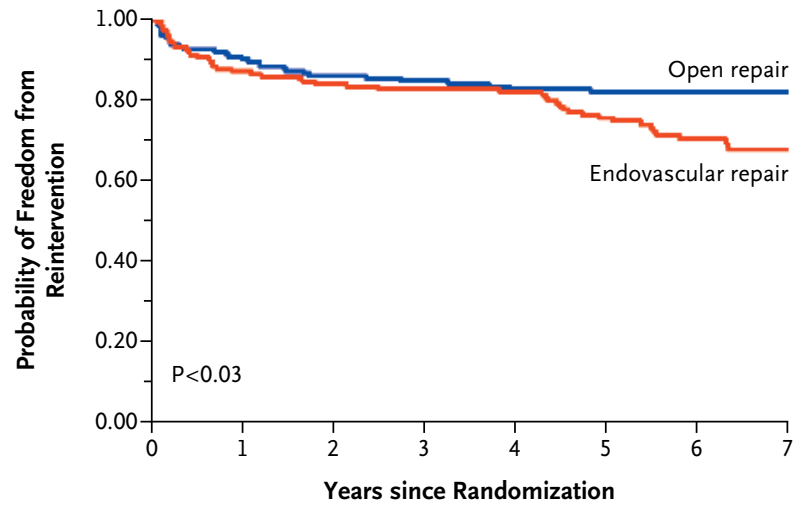

No. at Risk

$\begin{array}{lllllllll}\text { Open repair } & 178 & 152 & 139 & 128 & 118 & 111 & 73 & 29 \\ \begin{array}{l}\text { Endovascular } \\ \quad \text { repair }\end{array} & 173 & 147 & 134 & 123 & 115 & 102 & 66 & 31\end{array}$

Figure 2. Kaplan-Meier Estimates of Survival (Panel A) and Freedom from Reintervention (Panel B). dovascular Repair (OVER) trial (ClinicalTrials .gov number, NCT00094575) reported 2 years of follow-up on $80 \%$ of randomized patients but no 3 -year results. ${ }^{10}$ However, problems arising from limited durability of endovascular aneurysm repair are not expected to occur in the first 2 postoperative years. In our analysis of the DREAM trial data, not a single patient was lost to follow-up, and all surviving patients were followed for at least 5 years after randomization.

Retrospective hospital- and population-based studies with 9 years of follow-up after surgery have shown similar results. ${ }^{11-14}$ However, since these studies were not randomized, they all have a potential selection bias. The most important cause of bias is the potential association between the estimated short-term and long-term risks of death for a given patient, on the one hand, and the decision of the clinician to recommend open or endovascular repair, on the other.

In theory, inferior durability of endovascular repair, as compared with open repair, could mitigate long-term survival outcomes and thereby negate the short-term survival benefit of endovascular repair or even result in increased long-term risk. The cluster of reinterventions that appeared in the fifth year after endovascular repair is particularly troubling and casts doubt on the durability of endovascular devices. In our study, reinterventions that were performed more than 4 years after aneurysm repair were required because of endograft migration, limb thrombosis, or endoleak (type 1 or 2). The reintervention for an endograft limb occlusion followed by death a few days later illustrates the potential for reintervention to decrease patients' quality of life and increase the risk of aneurysmrelated death.

Despite this concern, graft-related complications and aneurysm rupture were not frequent causes of death in the long term. Therefore, we could detect no effect of graft complications on survival, a finding that may be a consequence of insufficient statistical power. Long-term and pooled analyses of the four randomized trials - DREAM, EVAR 1, OVER, and Anévrisme de L'aorte Abdominale: Chirurgie versus Endoprothèse $(\mathrm{ACE})^{15}$ - could have enough power to address this issue. However, it is also important to note that since the initiation of these trials, endovascular devices and techniques have undergone further modification, and with increas- 

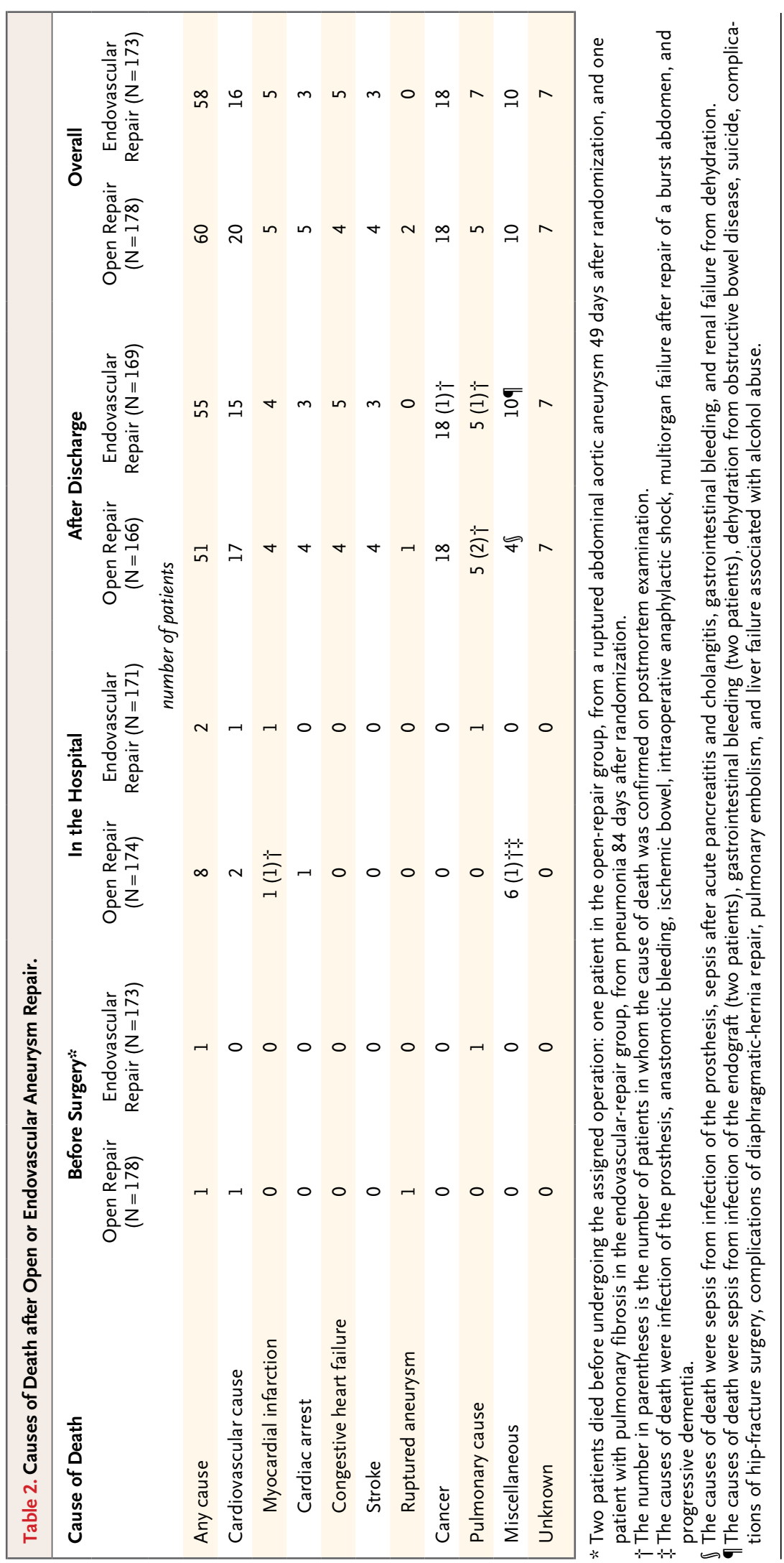

N ENGLJ MED 362;20 NEJM.ORG MAY 20, 2010 


\begin{tabular}{|c|c|c|c|}
\hline \multirow[t]{2}{*}{ Indication } & $\begin{array}{l}\text { Open Repair } \\
(N=178)\end{array}$ & $\begin{array}{l}\text { Endovascular } \\
\text { Repair }(N=173)\end{array}$ & $\begin{array}{c}\text { Total } \\
(\mathrm{N}=351)\end{array}$ \\
\hline & \multicolumn{3}{|c|}{ no. of patients } \\
\hline Any indication & 30 & 48 & 78 \\
\hline \multicolumn{4}{|l|}{ Graft-related indication } \\
\hline Any & 4 & 36 & 40 \\
\hline Thrombo-occlusive disease & 3 & 12 & 15 \\
\hline Endoleak type $1 *$ & 0 & 12 & 12 \\
\hline Migration & 0 & 7 & 7 \\
\hline Prosthesis infection & 0 & 2 & 2 \\
\hline Endotension & 0 & 1 & 1 \\
\hline Material failure & 0 & 1 & 1 \\
\hline Para-anastomotic aneurysm & 1 & 0 & 1 \\
\hline Aneurysm rupture & 0 & 1 & 1 \\
\hline \multicolumn{4}{|l|}{ Wound-related indication } \\
\hline Any & 15 & 3 & 18 \\
\hline Incisional hernia & 14 & 0 & 14 \\
\hline Wound infection & 1 & 2 & 3 \\
\hline Miscellaneous & 0 & 1 & 1 \\
\hline \multicolumn{4}{|l|}{ Local or systemic indication } \\
\hline Any & 11 & 9 & 20 \\
\hline Bleeding & 5 & 2 & 7 \\
\hline Endoleak type $2 *$ & $2 \dagger$ & 6 & 8 \\
\hline Bowel resection or ileus & $3 \ddagger$ & 0 & 3 \\
\hline Miscellaneous $\rrbracket$ & 1 & 1 & 2 \\
\hline
\end{tabular}

* In endoleak type 1 , which typically occurs early after surgery, an ineffective seal at the proximal or distal end of the endograft permits blood flow into the aneurysm sac. In endoleak type 2, retrograde flow from patent lumbar side branches causes flow into the aneurysm sac.

$\uparrow$ These two patients had crossed over from open repair to endovascular repair. Two resections were performed during the initial admission for open aneurysm repair. One patient underwent surgical repair for late bowel obstruction.

$\int$ One patient underwent reintervention because of a mass around the endovascular graft, as seen on computed tomography, but no infection was found. Histologic analysis showed signs of fibrosis. The other patient underwent an embolectomy of the popliteal artery, which was not graft-related. after aneurysm repair, and because only about one fourth of patients in the open-repair group underwent $\mathrm{CT}$ at 5 years (as compared with almost all patients in the endovascular-repair group), ascertainment bias probably contributed to the finding of more graft-related problems in the endovascular-repair group. Conversely, since it is not common practice to follow patients for more than 6 to 12 months after open repair, the elaborate follow-up protocol for all patients in the DREAM trial during the first 2 postoperative years may have led to an artificially high rate of early reintervention after open repair.

Another limitation of our trial concerns the relatively wide confidence interval for the difference in the primary outcome. On the basis of this interval, our results are consistent with a survival rate in the open-repair group that is as much as $10.8 \%$ higher or $8.8 \%$ lower than that in the endovascular-repair group. This imprecision is the inevitable consequence of the initial sample size and the numbers of patients remaining alive after 6 years of follow-up.

Not all patients with an abdominal aortic aneurysm are anatomically suitable for endovascular repair. Certain subgroups of patients (in terms of expected survival, coexisting illnesses, or various associated risk factors) may benefit more from one or the other type of aneurysm repair, but much larger trials or analysis of pooled data from the existing trials would be needed to identify these patients. Nevertheless, our study may help guide physicians and patients in choosing between open and endovascular repair, since our findings can be appraised in relation to various individual and personal circumstances.

In conclusion, our comparison of endovascular repair of abdominal aortic aneurysm with open repair showed similar long-term survival 6 years after randomization. There was a higher rate of secondary interventions in the endovascular-repair group.

ing experience, physicians have revised their criteria for identifying suitable candidates for endovascular repair. These changes may reduce the risk of complications requiring reintervention and thus increase long-term survival after endovascular repair.

Some limitations of our study should be noted. Because patients in the open-repair group did not undergo $\mathrm{CT}$ in the third and fourth years
Supported by the Netherlands National Health Insurance Council.

Dr. Buth reports receiving reimbursement for travel and accommodation expenses from Medtronic and Eurostar and payments for manuscript preparation from William Cook Europe, W.L. Gore, and Medtronic; Dr. Verhoeven, receiving payment for expert testimony, development of educational presentations, consulting and lecture fees, grant support, and travel and accommodation expenses from William Cook Europe and W.L. Gore and royalties from William Cook Europe; Dr. Cuypers, re- 
ceiving lecture fees from Medtronic; Dr. van Sambeek, receiving consulting fees from Medtronic and Cardialysis, research support from Medtronic, lecture fees from W.L. Gore, and travel grants from Medtronic and W.L. Gore; Dr. Balm, receiving consulting fees from Medtronic; and Dr. Blankensteijn, receiving consulting fees from Cordis and W.L. Gore. No other potential conflict of interest relevant to this article was reported. Disclosure forms provided by the authors are available with the full text of this article at NEJM.org.

We thank the Netherlands Society for Vascular Surgery, and Nicole Boekema and Lara Heuveling for their outstanding efforts in data management.

APPENDIX

Members of the DREAM trial study group are as follows: Steering Committee: D.E. Grobbee, J.D. Blankensteijn, A.A.A. Bak, J. Buth, P.M. Pattynama, E.L.G. Verhoeven, A.E. van Voorthuisen; Executive and Writing Committee: J.D. Blankensteijn, R. Balm, J. Buth, P.W.M. Cuypers, D.E. Grobbee, M. Prinssen, M.R.H.M. van Sambeek, E.L.G. Verhoeven, A.F. Baas; Data-Monitoring and Ethics Committee: M.G. Hunink, J.M. van Engelshoven, M.J.H.M. Jacobs, B.A.J.M. de Mol; Site and Device-Selection Committee: J.H. van Bockel, R. Balm, J. Reekers, X. Tielbeek, E.L.G. Verhoeven, W. Wisselink; Data Management: N. Boekema, L.M. Heuveling, I. Sikking; Outcome Adjudication Committee: M. Prinssen, R. Balm, J.D. Blankensteijn, J. Buth, P.W.M. Cuypers, M.R.H.M. van Sambeek, E.L.G. Verhoeven; Data Analysis: J.L. de Bruin, A.F. Baas, J.D. Blankensteijn, M. Prinssen.

The clinical centers that participated in the study are as follows (with the number of randomized patients in parentheses): the Netherlands: Catharina Hospital, Eindhoven (94) - J. Buth, A.V. Tielbeek; University Medical Center, Utrecht (35) - J.D. Blankensteijn; Academic Medical Center, Amsterdam (32) - R. Balm, J.A. Reekers; Erasmus Medical Center, Rotterdam (30) - M.R.H.M. van Sambeek, P. Pattynama; University Hospital, Groningen (27) - E.L.G. Verhoeven, T. Prins; St. Franciscus Gasthuis, Rotterdam (27) - A.C. van der Ham, J.J.I.M. van der Velden; Rijnstate Hospital, Arnhem (14) - S.M.M. van Sterkenburg, G.B. ten Haken; Leyenburg Hospital, 's-Gravenhage (9) - C.M.A. Bruijninckx, H. van Overhagen; Albert Schweitzer Hospital, Dordrecht (8) - R.P. Tutein Nolthenius, T.R. Hendriksz; Atrium Medical Center, Heerlen (8) — J.A.W. Teijink, H.F. Odink; Medical Center Rijnmond Zuid, Rotterdam (7) - A.A.E.A. de Smet, D. Vroegindeweij; Jeroen Bosch Hospital, den Bosch (7) - R.M.M. van Loenhout, M.J. Rutten; St. Elisabeth Hospital, Tilburg (5) - J.F. Hamming, L.E.H. Lampmann; Maxima Medical Center, Veldhoven (5) - M.H.M. Bender, H. Pasmans; Onze Lieve Vrouwe Gasthuis, Amsterdam (5) - A.C. Vahl, C. de Vries; Meander Medical Center, Amersfoort (4) - A.J.C. Mackaay; Vlietland Hospital, Schiedam (4) - L.M.C. van Dortmont; University Medical Center, Nijmegen (4) - A.J. van der Vliet, L.J. Schultze Kool; Martini Hospital, Groningen (3) - J.H.B. Boomsma, H.R. van Dop; Medical Center Haaglanden, 's-Gravenhage (3) - J.C.A. de Mol van Otterloo, T.P.W. de Rooij; Hospital Bernhoven, Oss (3) - T.M. Smits; Oosterschelde Hospital, Goes (3) - E.N. Yilmaz; Vrije Universiteit Medical Center, Amsterdam (2) - W. Wisselink, F.G. van den Berg; Leiden University Medical Center, Leiden (1) - M.J.T. Visser, E. van der Linden; University Medical Center, Maastricht (1) - G.W.H. Schurink, M. de Haan; Bronovo Hospital, 's-Gravenhage (1) - H.J. Smeets; Belgium: St. Jozef Hospital, Turnhout (4) — P. Stabel; St. Trudo Hospital, St. Truiden (3) — F. van Elst; University Hospital, Antwerp (1) - J. Poniewierski; University Medical Center, Ghent (1) - F.E.G. Vermassen.

\section{REFERENCES}

1. Prinssen M, Verhoeven EL, Buth J, et al. A randomized trial comparing conventional and endovascular repair of abdominal aortic aneurysms. N Engl J Med 2004;351:1607-18.

2. Greenhalgh RM, Brown LC, Kwong GP, Powell JT, Thompson SG. Comparison of endovascular aneurysm repair with open repair in patients with abdominal aortic aneurysm (EVAR trial 1), 30-day operative mortality results: randomised controlled trial. Lancet 2004;364:843-8.

3. Blankensteijn JD, de Jong SE, Prinssen $\mathrm{M}$, et al. Two-year outcomes after conventional or endovascular repair of abdominal aortic aneurysms. N Engl J Med 2005;352:2398-405.

4. EVAR Trial Participants. Endovascular aneurysm repair versus open repair in patients with abdominal aortic aneurysm (EVAR trial 1): randomised controlled trial. Lancet 2005;365:2179-86.

5. Leurs LJ, Buth J, Laheij RJ. Long-term results of endovascular abdominal aortic aneurysm treatment with the first generation of commercially available stent grafts. Arch Surg 2007;142:33-41.

6. Lederle FA. Endovascular repair of abdominal aortic aneurysm - round two. N Engl J Med 2005;352:2443-5.

7. Cronenwett JL. Endovascular aneurysm repair: important mid-term results. Lancet 2005;365:2156-8.

8. Prinssen M, Buskens E, Blankensteijn JD. The Dutch Randomised Endovascular Aneurysm Management (DREAM) trial: background, design and methods. J Cardiovasc Surg (Torino) 2002;43:379-84.

9. Clark TG, Altman DG, De Stavola BL. Quantification of the completeness of follow-up. Lancet 2002;359:1309-10.

10. Lederle FA, Freischlag JA, Kyriakides $\mathrm{TC}$, et al. Outcomes following endovascular vs open repair of abdominal aortic aneurysm: a randomized trial. JAMA 2009;302:1535-42.

11. Cao P, Verzini F, Parlani G, et al. Clinical effect of abdominal aortic aneurysm endografting: 7-year concurrent comparison with open repair. J Vasc Surg 2004; 40:841-8.

12. Schermerhorn M, O'Mally AJ, Jhaveri A, et al. Endovascular vs. open repair of abdominal aortic aneurysms in the Medicare population. N Engl J Med 2008; 358:464-74.

13. Brewster DC, Jones JE, Chung TK, et al. Long-term outcomes after endovascular abdominal aortic aneurysm repair: the first decade. Ann Surg 2006;244:426-38.

14. Peterson BG, Matsumura JS, Brewster DC, Makaroun MS. Five-year report of a multicenter controlled clinical trial of open versus endovascular treatment of abdominal aortic aneurysms. J Vasc Surg 2007;45:885-90

15. Becquemin JP. The ACE trial: a randomized comparison of open versus endovascular repair in good risk patients with abdominal aortic aneurysm. J Vasc Surg 2009;50:222-4.

Copyright (c) 2010 Massachusetts Medical Society. 